\title{
Imaginários de uma outra diáspora: consumo, urbanidade e acontecimentos pós-periféricos ${ }^{1}$
}

\author{
Rose de Melo Rocha \\ Josimey Costa da Silva \\ Simone Luci Pereira
}

Resumo: Este texto apresenta e discute alguns fenômenos que colaboram com a construção teórica do que denominamos "imaginários diaspóricos", sinalizadores de dinâmicas pós-periféricas e da circulação de fluxos culturais. A cena pós-periférica - que contextualiza fenômenos como os "rolezinhos", o "funk ostentação" ou os "pinta" natalenses - revela sujeitos de ação e de discurso capacitados a atuar em contextos fronteiriços.

Palavras-chave: comunicação; pós-periférico; consumo; imaginários urbanos.

Abstract: Another diaspora imaginaries: consumption, urbanity and post-peripheral events - This paper introduces and discusses some phenomena which collaborate with the theoretical construction hereby called "the diasporic imaginaries", signallers of post-peripheral dynamics and of cultural flow's circulation. The post-peripheral scenario, which gives room to phenomena like the "rolezinhos", "funk ostentação" and "pinta" in the city of Natal (RN), reveals subjects of action and speech who are capable of actuating among contexts of frontier.

Keywords: communication; post-peripheral; consumption; urban imaginaries.

\section{Movimentos da periferia, imaginários diaspóricos, cenas pós-periféricas}

Este artigo, em que pese o espaço restrito de argumentação, discute experiências brasileiras recentes caracterizadas pela circulação de complexos fluxos culturais e identitários. Estes, tanto colocam em jogo questionamentos ao status quo classista, xenófobo,

1 As ideias iniciais deste artigo foram apresentadas ao Grupo de Trabalho "Imagens e Imaginários Midiáticos" do XXIII Encontro Anual da Compós, na Universidade Federal do Pará, Belém, de 27 a 30 de maio de 2014. 
conservador, quanto podem significar o assujeitamento de jovens das periferias urbanas a padrões de gosto e reconhecimento social extremamente elitistas, hedonistas e individualistas. Entendemos que, nestes trânsitos simbólicos, tensões socioculturais ganham notoriedade, são negociadas e, eventualmente, reescritas. Articulando dois operadores conceituais - imaginários diaspóricos e contextos pós-periféricos -, analisamos tais fenômenos, que ganharam maior visibilidade social e enorme impacto midiático na contemporaneidade.

Neste contexto, o consumo material e simbólico de produtos, lugares e serviços convive com a promoção e apropriação de modelos estéticos, comportamentais e estilos de vida, configurando verdadeiros consumos-panoramas - para nos apropriarmos da conceituação de Appadurai (2004) -, atravessados por outros fluxos de imagens, imaginários e tecnicidades. Assim, falar de uma cena pós-periférica equivale, em primeiro momento, à identificação de um campo - cultural, midiático, social, estético e de consumo expandido, de bordas dilatadas e irregulares ${ }^{2}$.

Por outro lado, interpretar estratégias midiáticas massivas de representação das outridades periféricas (a periferia do mainstream, das cidades, do status quo branco, conservador, de classe média, e das classes dominantes) permite localizar pistas sobre atores aí implicados. São, assim, mapeadas ações juvenis de presença na cena pública urbana, com a mediação dos recursos tecnológicos e dos espaços digitais. Imaginários diaspóricos são postos em circulação, dinamizando processos pós-periféricos, com dinâmicas buttomup de significação - de si, dos outros, do mundo em que se vive. Escapa-se de noções de territorialidades delimitadas, atentando-se para as mesclas próprias aos contextos juvenis, urbanos e tecnológicos. A existência de um lugar tecnológico reticular e colonizado por narrativas autobiográficas contribui para acentuar e reconfigurar este trânsito. Isso nos permite até mesmo localizar o caráter fortemente discursivo dessas expressões diaspóricas e polifônicas que implodem o núcleo de algumas centralidades hegemônicas.

Existe também uma relação instável entre fluxos de imagens midiatizadas e produção imaginária individual e coletiva: tanto os imaginários dos moradores das periferias urbanas quanto os imaginários dos moradores de regiões não periféricas são afetados por produções imagéticas do Outro. Dialogando com a concepção de cosmopolitismo periférico (Prysthon, 2002), temos que as periferias são atravessadas por conteúdos e formas hegemônicos, e centralidades são igualmente permeadas por conteúdos, formas e valores periféricos.

A noção de periferia, articulada às advindas das teorias da subalternidade, do pós-colonialismo e dos estudos culturais, colabora para refletir sobre discursos da diferença e valorização de grupos minoritários no debate cultural e crítico contemporâneo, num ataque à hegemonia ocidental e central, que visa a superar a ideia de inversão total de cunho otimista e acrítico (como se a periferia virasse centro e vice-versa), mas que

2 Este espraiamento tanto pode significar uma real mobilidade, tal como apontado por Ferreira (2010), quanto implicar em possíveis estigmatizações. 
supõe espaços híbridos e intersticiais de negociação conflituosa de mundos e culturas, configurando-se como um lugar de onde se fala e se faz crítica cultural.

A noção de pós-periférico refere-se a um grau máximo dessa mescla. Acontecimentos complexos, como os "rolezinhos", os "pinta" natalenses e o "funk ostentação", tensionam categorias fixas e dicotômicas e nos alertam sobre a necessidade de um pensar contínuo sobre conceitos que permitam melhor observar e analisar objetos em trânsito, mais ainda em sociedades midiáticas, nas quais o hibridismo convive com a indiferenciação e a segregação. Pós-periférico não supõe a inexistência ou a superação de desigualdades e hierarquias, mas surge como categoria que busca ampliar e pensar as situações de imbricamento (para o bem e para o mal) de práticas e imaginários, não pela via territorial, mas pela via simbólica.

A cena pós-periférica pode revelar sujeitos de ação e de discurso (REGUILLO, 2000) plenamente capacitados a atuar em uma região de fronteira, o que, afinal, caracteriza o mundo do consumo e das mídias digitais, bem como o uso dos objetos da mobilidade - celulares, vídeos amadores, shows, marchas, mobilizações. O borramento de limites estanques entre política, padrões estéticos distintivos e diversão é óbvio e profundamente incômodo a setores que, por diferentes razões, se postam na condição de aduaneiros de tais universos. O grau e a natureza do incômodo aparecem em textos e imagens, dando gramatura a visões de mundo, a imaginários sociais, bem como a preconceitos e estigmas. Uma dessas coleções nos parece paradigmática de esforços higienistas e ordenadores. Reportagem especial da Revista Veja, de janeiro de 2014, apresenta a seus leitores as boas-vindas ao "país da periferia", aquele que seria "formado pelas classes C, D e E" e comporia um "universo de 155 milhões de pessoas que compram mais que a Suíça e a Holanda"³.

A periferia, que ganha essa visibilidade capciosa e que teria se espraiado por todo o país, como advoga a reportagem acima citada, tem sido bastante demarcada pela notoriedade adquirida pela atuação de jovens paulistanos, muitos deles experientes no trato da celebrização pós-massiva e que, antes dos "rolezinhos", já colecionavam fãs e "seguidores", características de messianismo pop tão familiares a processos de idolatria de sujeitos "comuns-incomuns". A periferia paulistana, até então conhecida publicamente por imagens e letras de grupos como os "Racionais $M C^{\prime}$ 's", é também a periferia de origem nordestina, como é, igualmente, a periferia profundamente mediatizada e perpassada por políticas públicas que reforçaram, nem sempre intencionalmente, a inclusão pelo entretenimento, pela ação cultural e intervenção urbana. Também é a que consome e domina uma peculiar cartografia de marcas e objetos, assim como inventou "lugares seus" em shopping centers, postos de gasolina, lojas de conveniência e lan houses (BORELLI, OLIVEIRA, ROCHA et al., 2009) .

Na história de jovens protagonistas de um trânsito não autorizado por templos do consumo material - os shopping centers - e por epicentros de consumo audiovisual

3 Revista VEJA. 29 de janeiro de 2014. Reportagem de Capa. Edição 2358. 
digitalizado - o Youtube e o Facebook -, brechas subjetivas estão ao lado de fraturas identitárias. A normatização, ou a tentativa de fazê-la, convive com a presença desestabilizadora, que escapa e desafia. A guerra é, mais uma vez, uma luta na seara das imagens, um enfrentamento da ordem das políticas de visibilidade. E, mais um dado, política aqui está visceralmente articulada ao campo do entretenimento. Em sociedades cujo regime dominante parece ser o de um capitalismo subjetivista e discursivo, não surpreende o fato de a política, ela própria, ter se tornado um caso de imagem, o que nem sempre vinha resultando em processos de visibilização de sujeitos sociais autônomos e ativos.

O discurso do empreendedorismo, tão caro aos valores neoliberais, frutifica agora junto a setores de neoincluídos. Será que estes o fazem para afirmar uma forma de autonomia que transita pendularmente pelo coletivismo autogestionário, pelo anarquismo pós-midiático e, outras vezes, pelas searas do narcisismo e do culto a super-eus, bens agora não mais exclusivos dos "bem-nascidos"? O consumo, atravessado por processos de midiatização do social, participa ativamente da repercussão alcançada por acontecimentos pós-periféricos, fenômenos de lastro "glocal", para lembrar o termo popularizado por Armand Mattelard. Todos querem se divertir. Muitos querem protestar. A polifonia daí resultante não é linear. Não propriamente revolucionária. Não necessariamente reacionária.

\section{Imaginários do consumo, corpo e identidades}

O imaginário, como algo indiscernível entre o real e o irreal, é também uma relação entre imagem e conceito que, para Deleuze (1992, 85), permite que as ideias se realizem ora em um, ora em outro plano. Na perspectiva de autores como Durand (1997) e Morin (1997), os imaginários dos indivíduos são também sociais, para além de sua natureza puramente mental e, portanto, se expressariam por meio de práticas concretas, por sua vez originárias de imaginários particulares. ${ }^{4} \mathrm{Na}$ proposta analítica deste artigo, os imaginários estariam também associados a práticas dotadas de politicidades e/ou expressividade pública, indicando disputas por hegemonia imagética e simbólica representativa de lugares sociais.

Como acessar formações imaginárias, senão por meio de suas expressões materializadas e disponíveis para análise? A cena, para além de suas práticas sociais localizadas temporal e espacialmente, engloba uma produção simbólica discursiva e esteticamente relevante. Os veículos jornalísticos registram versões dessas práticas e, atualmente, um meio preferencial para difusão e registro dessa produção por parte dos jovens e para suas repercussões é o digital, com especial destaque para as mídias sociais. Até mesmo a celebridade alcançada por muitos desses jovens e o poder de mobilização de grandes grupos têm na internet o principal veículo. Recolher as repercussões midiáticojornalísticas dessas práticas e as recorrências de postagens no espaço digital permite

4 Para melhor entendimento dessas formulações, consultar SILVA, Josimey Costa da. Sobre o imaginário. Disponível em < https://www.google.com.br/webhp?sourceid=chrome-instant\&rlz=1C1CHWL_ptBRBR612BR613\&ion=1 \&espv=2\&ie=UTF-8\#q=imagin \%C3\%A1 rio\%20filocom $>$. Acessado em 05 nov. 2014 .. 
uma maior aproximação de um fenômeno que se destaca dentro de muitas outras práticas juvenis contemporâneas.

Assim, foram investigadas manifestações ocorridas em São Paulo-SP, Rio de Janeiro-RJ e Natal-RN arquivadas na internet, em razão de sua recorrência no noticiário jornalístico comercial ou nas postagens feitas por jovens que representam ou citam o tipo de ator social em foco. Foram consultados 05 perfis no Facebook, 10 blogs, 08 versões online de páginas de jornais e 05 de revista, 03 sites de conteúdo colaborativo e 05 canais

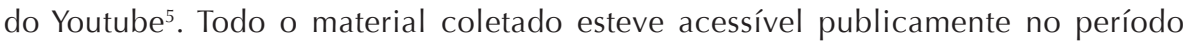
da pesquisa, ocorrida nos meses de janeiro e fevereiro de 2014.

Como orientação metodológica para a pesquisa qualitativa que realizamos, partimos do pressuposto de que a teoria deve lançar luz sobre práticas concretas, possibilitando compreendê-las sem organizá-las conforme pressupostos idealmente sistematizados. Consoante o proposto por Morin (2001), uma disciplina fechada em si mesma origina um método que só pode elucidar um segmento muito limitado da realidade, mas não um fenômeno complexo, como é o caso, no nosso entendimento, das práticas juvenis contemporâneas.

A utilização dos princípios da complexidade como referência teórica e método de pesquisa implica a subjetividade do pesquisador na investigação, assim como a ação de um sujeito sobre o mundo como parte dos fenômenos a investigar. A inclusão da subjetividade como parte da realidade considera que a diversidade, a incerteza, a ambivalência e os antagonismos são elementos indissociáveis dos fatos, da observação e do observador. Propondo o uso do termo "método" ao invés de "metodologia", que é apropriada como modelo a ser seguido, Morin (2008, p. 36) sugere que o método só pode ser construído durante a pesquisa, o que exige rigor e não rigidez, e ainda mais: só pode emanar depois dela e como um novo ponto de partida.

Com essa aposta política e cognitiva, procuramos elaborar um metaponto de vista sobre as subjetividades dos jovens vinculados à estética funk em movimentos de afirmação social nos lugares e espaços pesquisados. Em análise de natureza documental em meio digital e utilizando os apontamentos de Bauer e Gaskell (2002), recolhemos amostras representativas simbolicamente de postagens e de publicações jornalísticas sobre as manifestações em foco. Como parâmetro de escolha, utilizamos o viés discursivo hegemônico das repercussões midiáticas sobre o fenômeno. Assumimos que a representação da alteridade exótica e a rejeição a padrões estéticos e comportamentais estão imbricadas ao funk como manifestação cultural e social no Brasil. Também foram utilizados os recursos da netnografia, segundo Kozinets (2010), ou etnografia virtual, que levou em conta práticas de consumo midiático a partir da observação das postagens em comunidades virtuais para avaliar tanto a autoexpressão de jovens ligados ao funk quanto as reações a isso por parte de outros tipos de jovens, no intuito de acompanhar aspectos

5 Por razões de limitação de espaço para este artigo, apenas os endereços diretamente citados no texto estão indicados a seguir. 
da repercussão social como parte do fenômeno. Com apoio dos princípios da complexidade e a partir de uma leitura do fenômeno como multimodal (O'HALLORAN \& SMITH, 2011), interpretamos os documentos assim recolhidos com o aporte dos embasamentos teóricos de diferentes disciplinas (Comunicação Social, Teoria da Mídia, Sociologia, Antropologia, Semiótica da Cultura, Teoria Política, Psicologia e Filosofia, entre outras).

O objetivo era acompanhar manifestações discursivas sobre tipos de jovens identificados como integrantes de movimentos pós-periféricos sob o eixo unificador da estética funk. Em Natal, a investigação apontou para um tipo intitulado "pinta" natalense, que protagonizou movimentos de natureza semelhante aos "rolezinhos" paulistas em um dos shopping centers da cidade, o Midway Mall, com reações registradas nas mídias digitais e cobertura pela imprensa jornalística tradicional. O estilo de consumo desse tipo de jovem, sua origem social e seu comportamento - que inclui um modo específico de apresentação visual - provocaram hostilidades por parte de jovens de outros extratos sociais em comunidades on line na rede social Facebook.

No Facebook, o perfil Todo natalense ${ }^{6}$ está na categoria "entretenimento" e é autodefinido como uma página "potiguar pra informar e entreter, coisa séria e humor sarcástico, feita por quem é apaixonado por essa cidade". No final de 2013, o proprietário do perfil fez uma postagem que gerou 1.096 curtições, 137 comentários e 53 compartilhamentos, entre defesas acaloradas e críticas contundentes.

Entre as respostas, uma das mais enfáticas foi a de J. B.: a "pior coisa nos fins de semana é pegar o 63 [linha de ônibus urbano de Natal que liga bairros da zona sul à zona norte da cidade] e vê aqueles Pintas escutando Funk, antes era grafite, agora é Funk, ninguém merece isso!" No final de 2013, blogs noticiaram brigas, protestos e reforço de policiamento, todos referentes à frequência de jovens da periferia ao shopping. As imagens estão em vídeos na Internet, como no canal Noz Inventa, do Youtube? . Em 21 de dezembro de 2013, os diários Tribuna do Norte e Novo Jornal noticiaram que o "Protesto dos Pintas", uma manifestação marcada pelas redes sociais, foi coibido com violência ${ }^{8}$.

Para os natalenses, o termo "pinta" é familiar e designa jovens que fogem ao modo de vestir usual daqueles com padrão de consumo médio e alto. Em geral, quem se veste assim mora em bairros periféricos, na zona norte da cidade, estudou em escolas públicas ou comunitárias ou ainda é universitário com postura política afirmativa em favor da justiça social. Segundo o blog Carta Potiguar, o "pinta é o único personagem tipicamente natalense. Sua vestimenta comumente identificável - bermuda de praia, camiseta folgada,

6 In: https://www.facebook.com/TodoNatalense. Postagens em 30/11/2013. Consultado em 11 fev. 2014.

7 n: http://www.youtube.com/user/nozinventa?feature=watch. Consultado em 11 fev. 2014. “Protesto Dos Pintas - 21/12/2013. In: http://www.youtube.com/watch?v=nHrCJX-TiFM. Consultado em 11 fev. 2014.

8 "Protesto dos 'pinta' acaba em confusão no Midway". In: http://tribunadonorte.com.br/news.php?not_id=270046 ; "Protesto acaba em confusão no Midway Mall: a manifestação "Protesto dos Pintas" foi marcada há duas semanas nas redes sociais; confronto entre policiais e manifestantes gerou a detenção de cinco pessoas. Publicado em 21/12/2013. In: http://www.novojornal.jor.br/_conteudo/2013/12/cidades/25326-protesto-acaba-em-confusaono-midway-mall.php. Consultados em 11 fev. 2014. 
boné - é perfeitamente adaptada ao clima de uma cidade quente e praieira (...) O "pinta" é essencialmente um antiplayboy." ${ }^{\prime 9}$ Em geral, ouve, como estilos de música preferidos, forró, suingueira ou funk, às vezes também música sertaneja ou brega. Se for universitário, pode ouvir tudo isso ou reggae, MPB, rock. Na aparência e na atitude, o "pinta natalense" se aproxima dos funkeiros da ostentação, dos "reis do rolezinho" de São Paulo e dos meninos do "passinho"10 no Rio de Janeiro.

Em 2008, em Natal, os jovens dos bairros periféricos já frequentavam o shopping center Midway Mall, que é passagem para ônibus que ligam todas as zonas da cidade. A frequência a centros de consumo antes interditados socialmente é uma atitude que caracteriza o "rolezinho", assim como as referências a um alto consumo encontradas no funk ostentação. "A periferia se cansou de esperar a oportunidade que nunca chegava, e que viria de fora, do centro", manifestou-se, em 2007, Hermano Vianna ${ }^{11}$, numa frase que ainda hoje serve de epígrafe ao blog Periferia em movimento: cultura, ação e cidadania, coletivo de comunicação sobre, para e a partir das periferias. Segundo o blog, o funk é, atualmente, um estilo musical que se divide em muitas vertentes. São citadas as do funk ostentação, a consciente, a sensual e a de apologia às drogas e à violência. A cada uma dessas vertentes, corresponde um estilo de apresentação visual, um modo de falar distintivo e uma gramática própria, semelhantes entre si, mas diferenciados em relação a outros movimentos culturais e sociais que, no segmento jovem da população, estão sempre profundamente ligados à fruição identitária e performática de gêneros musicais.

A música e a moda ligadas a esses movimentos geram eventos que dão visibilidade aos seus protagonistas e a outros moradores dos bairros periféricos, extrapolando os limites territoriais. A afirmação do eu em estilos próprios e marcadamente distintivos é a principal emergência desse tipo de atitude, que pode ser encontrada em muitos jovens dessa que hoje é uma pós-periferia. Ao nos apropriarmos do pensamento de Heidegger - para quem não são os conceitos, mas é o cotidiano que nos aponta os problemas fundamentais -, percebemos que, nesse cotidiano, ser é "ser com os outros". Esse é o "ser no mundo", em sua cotidianidade e fascinado por esse mundo que é o seu. Um ser que não pode ser uma simples presença objetivada, mas, antes, se apresenta como uma modificação existencial do "a gente" (HEIDEGGER, 1981). Nas diásporas pós-periféricas, é esse "a gente" que está em questão.

\section{Funk ostentação}

A cobertura massiva sobre os "rolezinhos" destacava as preferências culturais dos participantes, em particular a música escutada e cantada durante os "rolês". Numa clara

9 "O pinta: cidadão natalense". PorTúlio Madson. Publicado em 18/12/2013. In: http://webcache.googleusercontent. com/search?q=cache:http://www.cartapotiguar.com.br/2013/12/18/o-pinta- cidadao-natalense/

10 Dança livre de jovens das comunidades dos morros e da periferia cariocas que mistura estilos do break, do funk, da salsa e outros.

11 Em manifesto originalmente publicado na Revista Raiz - cultura do Brasil, em 02/01/2007. In:

http://revistaraiz.uol.com.br/portal/index.php?option=com_content\&task=view\&id=220\&ltemid=180.Consultado em 11 fev. 2014. 
construção da alteridade exótica, o que se percebe em muitas publicações - como já apontado no caso do funk carioca por Trotta (2014), Sá (2007), entre outros - é a sensação do estranhamento e até da repulsa por um diferente, um apêndice do país, numa estratégia discursiva que segrega o subalterno, construindo múltiplas imagens e imaginários (ligadas à violência e à pobreza) deste espaço geográfico e social que é a periferia, algo que não parece pertencer ao país ideal do discurso midiático hegemônico. No que tange à escuta e à paisagem sonora (Pereira, 2012) desta periferia, o que se diz constantemente nas representações midiáticas e no senso comum é sobre sua qualidade inferior, a falta de elementos estéticos e de distinção associados à chamada "boa música" e sua associação a algo comercial, de entretenimento vazio e alienante.

Pelo que estudiosos da periferia de São Paulo nos contam, um dos estilos ou gêneros de música mais consumidos por estes jovens é o chamado "funk ostentação" ${ }^{12}$. Derivado do "funk proibidão" carioca ${ }^{13}$, com ideário explícito de alusão e promoção da criminalidade, das drogas e da violência, a versão "ostentação" traz alusões ao consumo de grifes famosas, ao dinheiro, às bebidas, aos carros e às mulheres, associado a um padrão de vida e consumo das classes altas, em videoclipes musicais (forma privilegiada de divulgação dessa música), que lembram o gangsta rap norte-americano. Os videoclipes mostram jovens rodeados por esses ícones luxuosos, cobertos por correntes e anéis de ouro e por roupas, óculos e bonés de grifes como Oakley, Hyundai, Rolex, Tommy Hilfiger, Armani, Lacoste, entre outras, em que certo imaginário de sucesso, prestígio, inclusão mostra-se como um forte componente ligado ao consumo ${ }^{14}$.

Já se tornou uma narrativa comum e aceita pelos seus próprios protagonistas compreender o funk ostentação como algo paulista, criado em meados da década passada na Baixada Santista por MCs como Boy do Charme ("Onde eu chego paro tudo") e trazida para São Paulo em 2006. A partir daí, espalhou-se pela periferia paulistana (principalmente a Zona Leste), contando com diversos MCs (Guimê de "Plaque de 100", Bio G3 e o "Bonde da Juju", Dede e "Olha o Kit", Rodolfinho e "Como é bom ser vida loka", Menor do Chapa e "Sou patrão, não funcionário", do Rio de Janeiro, Daleste, assassinado no palco durante show em Campinas em 2013, entre outros),

12 Referência à pesquisa de Alexandre Barbosa Pereira, da UNIFESP.

13 Segundo Carlos Palombini (em entrevista concedida a Simone Luci Pereira em fevereiro/2014), o "ostentação" é uma característica do funk "proibidão" carioca há pelo menos sete anos, quando já se encontravam alguns versos ou estrofes dedicado "à opulência da vida no varejo de substâncias ilícitas". Segundo esse autor, a ostentação per se, sem associação explícita com o varejo de substâncias ilícitas, resulta: 1. Da prisão dos MCs Frank, Max, Tikão, Didô e Smith em 15 de dezembro de 2010; 2. Das invasões e da ocupação dos Complexos da Penha e do Alemão no final de novembro de 2010, e do consequente desaparecimento de muitos bailes de comunidade, entre eles, o principal, o da Chatuba; 3. Do fato que, sem bailes para realizar no Rio, e com a facção responsável pela narco-cultura brasileira maciçamente ameaçada, vários MCs cariocas encontraram mercado de trabalho em São Paulo

14 Alexandre Barbosa Pereira salienta que, no caso do proibidão e do ostentação, está presente, de modos diferenciados, um mesmo aspecto da realidade dos jovens das periferias: a presença do consumo e da violência, em diferentes formas de imaginação e experimentação. Disponível em: http://brasil.elpais.com/ brasil/2013/12/23/opinion/1387799473_348730.html. Acesso em fev. 2014. 
produtores de videoclipes e shows, e até um documentário lançado em 2012, "Funk O\$TENTAÇÃO - o Filme"15.

Sobre os videoclipes, é notável o investimento em produções lançadas no Youtube, gerando até trinta milhões de acessos em cada música, demonstrando usos das mídias digitais e da internet alternativos aos do mainstream (não apareciam até agora na grande mídia e tampouco gravam cds), baseando-se nos shows em casas noturnas (com até cinco apresentações por noite) e views na internet, fazendo sua divulgação em flyers distribuídos na periferia (bairros como Cidade Tiradentes, Guaianazes, Itaquera) e em redes sociais, como Facebook e Twitter.

A Kondzilla (de Konrad Dantas, jovem de 25 anos, morador da Cidade Tiradentes) e a Funk TV (que realizou vários videoclipes do MC Daleste) são empresas produtoras de muitos dos videoclipes musicais, especializadas em produzi-los numa estética semelhante àquela do gangsta rap e de boa qualidade técnica, antes não vista em produções dessas músicas, numa intenção de afirmar "bons valores" da periferia e não a criminalidade e as drogas.

Essa questão nos chama a atenção pelo fato de serem os funkeiros falando sobre eles mesmos nos clipes e no filme; não supomos aqui uma narrativa, por este motivo, livre, revolucionária, resistente aos discursos hegemônicos, mas salientamos a possibilidade de representações contra-hegemônicas que, de alguma forma, provocam dissonâncias e fissuras no discurso hegemônico ao buscarem sua inserção via consumo e afirmação de um imaginário das classes altas, mas, ao mesmo tempo e apesar disso, buscarem ocupar um lugar que sempre Ihes foi negado. Segundo Enne, isso enfatiza o:

caráter hegemônico e consensual das representações veiculadas pela indústria cultural e o movimento contra- hegemônico e conflitivo das representações que se espalham pela internet, evidenciando o quanto o campo das representações é arena de disputas discursivas em torno da política e da identidade, dentre outros eixos, algumas vezes implicando em negociações e emparelhamentos de sentido complexos e problemáticos. (ENNE, 2013, p. 177)

Um paradoxal potencial político vai se esboçando em fenômenos como esse, com sua possibilidade de cooptação pelas classes médias e altas como sendo um "funk do bem", domesticado e mais palatável em ideários que corroboram o status quo, tocado em casas noturnas elitizadas por não exaltar a criminalidade e sim o consumo e o sucesso. Ao mesmo tempo, mostra também sua potência ao tentar romper com aspectos de distinção e exclusividade ligados ao consumo, reivindicando a inclusão em espaços reais e simbólicos onde a noção de separação de habitus e padrões de vida é menos nítida no uso que esses jovens fazem das marcas e dos imaginários das elites socioeconômicas.

15 Disponível em:< http://www.youtube.com/watch?v=5V3ZK6jAuNI> Acesso em 12 mar. 2014. 
De acordo com Alexandre Barbosa Pereira ${ }^{16}$, não há total separação entre o rap paulistano "consciente" dos anos 1990, associado à politização, à crítica social e à resistência, e o funk ostentação, exaltando explicitamente lazer, consumo, luxo e entretenimento, considerados alienantes. De acordo com o antropólogo, muitos rappers aderiram ao "ostentação", sendo que, nos shows de funk da atualidade, escuta-se também músicas de grupos como Racionais MC, ícones do rap político. O que esse fato parece lembrar é que esses referenciais musicais se confundem na escuta dos jovens que vão aos shows e que cantam e consomem essas músicas, uma vez que, em ambos os casos, o que surge para eles é o potencial de afirmação e autoestima da periferia pela via musical, seja num tom mais sério e contestador, seja num tom de entretenimento e de leveza que os carros luxuosos, as marcas de roupas, os óculos, os relógios parecem querer trazer para a presença cotidiana.

\section{Considerações Finais}

Em tempos de crescente apelo às dicotomias e às literalidades, chama atenção a sistemática tentativa de veículos de comunicação tradicionais de disseminar circunscrições discursivas de regulação e reincorporação estetizada de fenômenos como os "rolezinhos" que, do mesmo modo que a expressão menos famosa "pinta" natalense, guardam uma relação estreita com as expressões do funk no Brasil, gênero musical e prática cultural que também aglutina todo um campo de estilização visual e sonora. O lado B, que parece estar sendo associado às anomias e rupturas advindas de práticas culturais e de sociabilidade articuladas a recentes processos de inclusão pelo consumo, tem composto a agenda midiática massiva.

Essa empreitada de regulação audiovisual lembra-nos uma polêmica tese de Lyotard (1994), para quem, ao contrário do que comumente imaginamos, a forma mais efetiva de apagar fatos da memória é representando-os, repetidamente, excessivamente, de todos os ângulos possíveis, em seus mínimos detalhes. O filósofo ancora sua argumentação em um dos mais sangrentos capítulos da história mundial, o genocídio dos judeus pelos comandos nazistas. Para o autor, as políticas de esquecimento absoluto empreendidas pelos SS dependeram não apenas do ocultamento, mas posteriormente do agenciamento da representação.

O que acontece quando a empresa da representação se descentraliza? E quando a mídia massiva é confrontada pela multiplicação exponencial de uma ampla, plural e movente cena digital? Estudos recentes têm apontado a centralidade ocupada pelas materialidades advindas do consumo e dos meios de comunicação, em especial as de natureza tecnológica, na composição, desde ao menos quatro décadas, dos modos de ser e de viver de inúmeros segmentos juvenis no Brasil. Em direção similar, também se registra a atuação dos processos de visibilidade midiática na caracterização de experiências e

16 Em entrevista a Eliane Brum. Disponível em: http://brasil.elpais.com/brasil/2013/12/23/ opinion/1387799473_348730.html. Acesso em mar. 2014. 
identidades tipificadas como juvenis, tanto no que diz respeito aos processos de produção e validação de representações e de promoção de estilos de vida, quanto na apropriação de conteúdos e meios de comunicação para produzir e divulgar ações de protagonismo juvenil (ROCHA, 2012).

Como lembra Alexandre Barbosa (em entrevista já citada), a reivindicação pelo direito a "zoar" na cidade (gerando uma disputa por espaços na metrópole) e pelas músicas, ainda que não possa ser encarada como libertadora e nem, opostamente, como vilã alienante, aparece como uma forma de insubordinação tácita, ainda que lazer, entretenimento e consumo não se mostrem como ações e motivações políticas clássicas, esperadas ou desejadas, apontando para uma potência contraditória e paradoxal destes fenômenos (rolezinho, pintas e funk ostentação) e de suas práticas cotidianas correlatas. Trotta (2013) alude com razão à emergência da periferia na cena musical contemporânea, ressaltando o quanto ela surge de maneira positivada, permitindo (re)elaborar assimetrias e pertencimentos desiguais. Concordando com o autor, talvez pudéssemos pensar em realidades pós-periféricas para refletir sobre esta presença midiática positivada até certo ponto, que desafia lógicas excludentes entre centro/periferia e maisntream/independente.

Pensando com Appadurai (2004) e seus panoramas/paisagens que acionam a "obra da imaginação" - como característica constitutiva da subjetividade moderna, ajudando a criar novos imaginários sociais que misturam, articulam e colocam em confronto diferentes fluxos -, salientamos que esta não se coloca como puramente emancipatória e nem totalmente disciplinada, mostrando-se como um espaço de negociação no qual as noções de diferença, alteridade, e também de subalternidade e de periferias se impõem para refletirmos sobre esses deslocamentos e essas diásporas que envolvem espaços geográficos e semânticos, em pauta neste artigo.

As relações entre consumo, estética, entretenimento e política vão se mostrando em associações conflituosas e que exigem uma atenção às contradições, descontinuidades e complexidades que trazem à tona sobre juventudes, formas de protagonismo, usos midiáticos, dentre outros aspectos. Se a exaltação de marcas e ideários do consumo no funk ostentação aponta para uma possível domesticação das músicas dos jovens da periferia, retirando-Ihes o potencial revolucionário, o consumo motiva formas de ser, estar, pensar e se inserir no mundo contemporâneo, onde a reinvindicação de lugares e símbolos exclusivos das classes altas desafia certo moralismo acadêmico que insiste em tutelar os gostos, costumes e hábitos das classes baixas a um padrão iluminista e letrado. Refletir sobre realidades pós-periféricas mostra-se como um caminho que, longe de abolir as hierarquias reais, simbólicas e discursivas, aponta para cenários em que as fronteiras rígidas entre centro e periferia se encontram mais borradas e menos nítidas, exigindo uma perspectiva epistêmica que possibilite a compreensão de realidades complexas. 
Rose de Melo Rocha é professora do PPGCOM-ESPM.

rrocha@espm.br

Josimey Costa da Silva é professora do PPGEM e PPGCSO daUFRN.

josimeycosta@gmail.com

Simoni Luci Pereira é professora do PPGCOM-Unip e colaboradora do PPGCOM-ESPM.

simonelp@uol.com.br

\section{Referências}

APPADURAI, A. Dimensões culturais da globalização. Lisboa: Teorema, 2004.

BORELLI, S.; OLIVEIRA, R.; ROCHA, R. et al. Jovens na cena metropolitana. São Paulo: Paulinas, 2009.

ENNE, A. Representações sociais como produtos e processos: embates em torno da construção discursiva da categoria "vândalos" no contexto das manifestações sociais no Rio de Janeiro em 2013. Revista História e Cultura, Franca-SP, v.2, n.2, p.174-196, 2013.

DELEUZE, G. Dúvidas sobre o imaginário in Conversações. Rio de Janeiro: Ed. 34, 1992.

DURAND, G. As estruturas antropológicas do imaginário: introdução à arquetipologia geral. Lisboa: Ed. Presença, 1997.

FERREIRA, J. Cultura das bordas: edição, comunicação, leitura. São Paulo: Ateliê, 2010.

HEIDEGGER, M. Todos nós... ninguém: um enfoque fenomenológico do social. São Paulo: Moraes, 1981.

KOZINETS, R. Netnography: Doing Ethnographic Research Online. London, Sage, 2010.

LYOTARD, J-F. Heidegger e os judeus. Petrópolis, Vozes, 1994.

MORIN, E. O cinema ou o homem imaginário. Lisboa: Grande Plano, 1997.

O método 1. Porto Alegre: Sulina, 2008.

. A religação dos saberes: o desafio do século XXI. Rio de Janeiro: Bertrand Brasil, 2001.

O'HALLORAN, K. \& SMITH, B. (eds). Multimodal Studies: Exploring Issues and Domains. New York \& London: Routledge, 2011.

Os novos 'vândalos' do Brasil. Artigo de Eliane Brum com entrevista de Alexandre Barbosa. Acesso em fevereiro de 2014. Disponível em http://brasil.elpais.com/brasil/2013/12/23/ opinion/1387799473_348730.html

PEREIRA, S. Sobre a possibilidade de escutar o outro: voz, world music, interculturalidade. Revista E-Compós. vol. 2, n.15, 2012.

PRYSTHON, A. Margens do mundo: a periferia nas teorias do contemporâneo. Revista Famecos. vol. 1, n. 21, 2003. 
REGUILLO, R. Emergencia de culturas juveniles. México: Editorial Norma, 2000.

ROCHA, R. Juventudes, comunicação e consumo: visibilidade social e práticas narrativas. In: Juventudes e gerações no Brasil contemporâneo. Lívia Barbosa (org.). Porto Alegre: Sulina, 2012 (p. 238 -276).

SÁ, S. Funk carioca: música eletrônica brasileira? Revista E-Compós, v.10, 2007.

SILVA, J, NEVES, T. e SOBRAL, G. Jovens: imagens de presença e ausência na cultura. In: Ensaios de complexidade 3. Maria da Conceição Almeida e Alex Galeno (orgs). Natal: EDUFRN, 2012 (p. 40-52).

TROTTA, F. Entre o Borralho e o Divino: a emergência musical da 'periferia'. Galáxia. Revista do Programa de Pós-Graduação em Comunicação e Semiótica da PUC/SP. v.13, n.26, 2013.

. A música que incomoda: o funk e o rolezinho. Anais COMPÓS 2014. Belém: Compós, 2014.

Artigo recebido em agosto de 2014

e aprovado em março de 2015. 